\title{
Ser ator no Oficina
}

To be an actor in Oficina

\section{Marcelo Drummond}

Marcelo Drummond Ator e encenador do Teatro Oficina

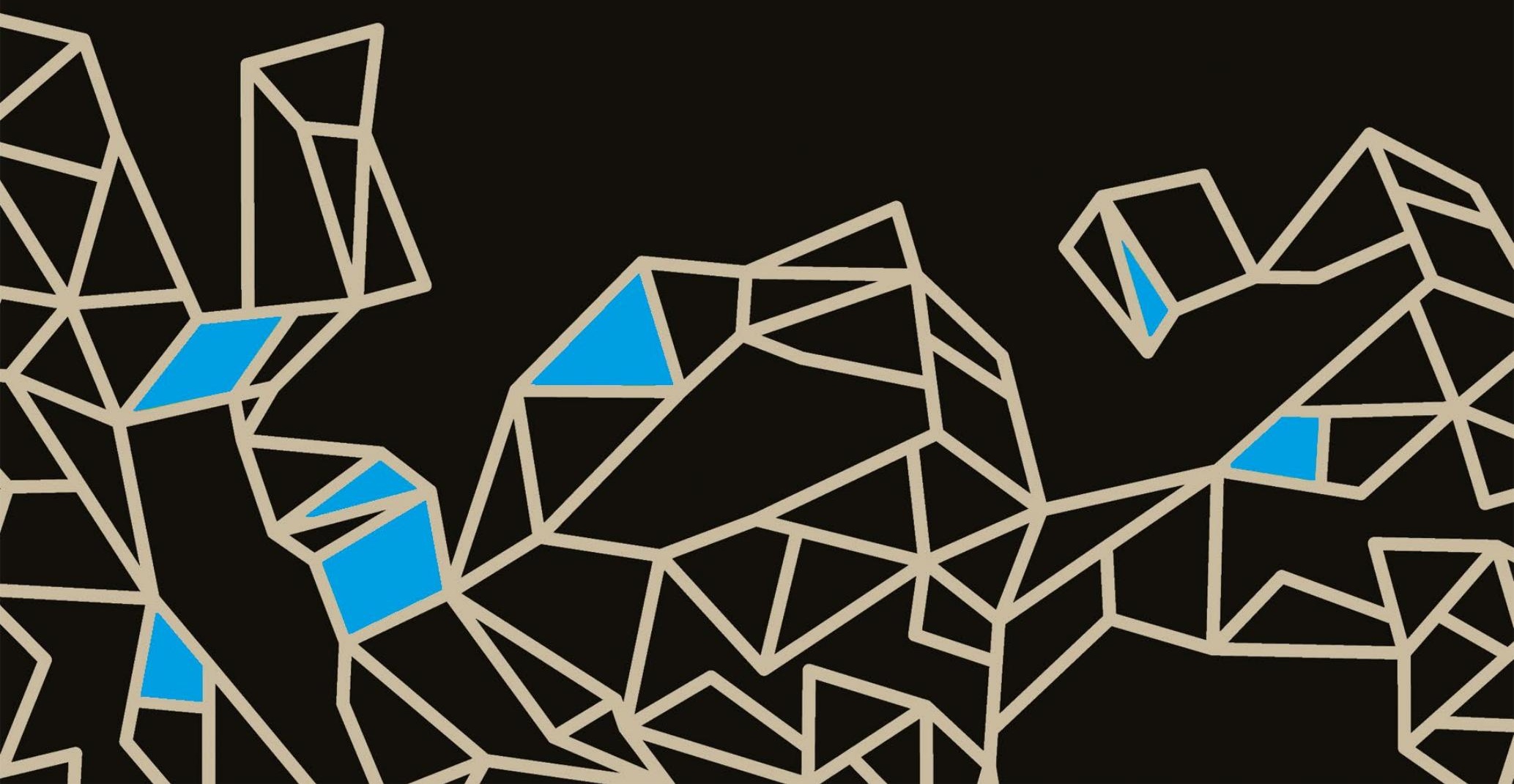


Como escrever um texto sobre ser ator no Oficina? Não sei. Alguns me chamam de primeiro ator do Oficina, um título que me foi dado porque o Oficina, de fato, entrou em cena de novo junto comigo, na época um jovem que não sabia nada contracenando com Raul Cortez e Zé Celso, ou fazendo o Hamlet (uau, que pecado!) e desde então fiquei à frente como ator/produtor e, às vezes, diretor, mas nunca sozinho com Pascoal da Conceição, Camila Mota, Sylvia Prado e muito mais gente porque é um trabalho coletivo, com isso quer dizer que ninguém é mais estrela que ninguém na hora do trabalho e também sempre é bom lembrar que um ator da moda e com o maior sucesso agora pode estar no ostracismo num futuro não muito distante.

Cheguei no Teatro Oficina em 1986, vim pra fazer o deus do teatro Dionysios (na grafia que usamos), claro que isso é uma pretensão! Mas foi isso mesmo, não a pretensão, mas o fato. Tive dois mestres, por assim dizer, porque nunca os chamei de mestres e eles não aceitariam, o Zé Celso, que é público, e Catherine Hirsch, que me ensinou o teatro como rito onde se nasce e morre pra nascer novamente, as muitas vidas que se pode ter no teatro, me ensinou mais ainda. Tudo que sei do fazer teatral aprendi no Oficina, com os "mestres" e outros atores-diretores-produtores e críticos mestres também. Não fiz, não me interessei em fazer uma "carreira de ator", correndo atrás de um espaço na televisão, (agora streaming) pra ficar conhecido, rico e poder produzir o que quer ou simplesmente ficar empregado... preferi ser criador e trabalhar pro que eu quero. E até agora quero o Teatro Oficina funcionando, produzindo peças, filmes, música, podcast e lives.

Todo o trabalho do Oficina Uzyna Uzona, antes da pandemia, foi guiado por Dionysios-Bacantes, nesse momento ensaio Esperando Godot, esperando a vacina e apreensivo pelo teatro que virá depois da pandemia. Ainda não sabemos por quanto tempo não poderemos fazer o teatro que fazíamos antes da pandemia, acredito que nos próximos anos não; a proximidade e a participação ativa, de corpo presente, do público, aglomerado nas arquibancadas, galerias invadindo a pista, as mais de 60 pessoas circulando pelos camarins apertados, dividindo bancadas, banho, maquiagem, copo, respirando pertinho... em cena um coro cantando a menos de dois metros de uma pessoa do público, fora os abraços, beijos, zeselfie, bares e tudo mais que envolve a orgia da Tragicomediorgia. O que me motiva a fazer teatro é o acontecimento, o rito, a peça, o público, a bilheteria, a magia do teatro. 
O teatro é um lugar de incorporação, assim como as religiões de incorporação, são outros métodos, já vi e vivi no Oficina a personagem ali, na tua frente, atores incorporados, entregues aos próprios delírios. No Brasil tem cultura de incorporação, dionisismo é religião de incorporação, como é a umbanda, que é superteatral, aquelas "entidades" incorporadas, com cantos, dança, comida e bebida; os rituais com Ayahuasca, as mirações, até nos cultos evangélicos, onde tem sempre alguém que "recebe" o demônio. As Bacantes de Eurípedes, que foi escrita na Macedônia, onde se exilou com o amigo (talvez amante) Agatão, ali ouviu e registrou os cantos de terreiros de uma antiga religião dionisíaca. Quando fizemos a primeira temporada de Bacantes, em 1996, bebíamos ayahuasca, porque sabemos que o vinho que era servido nos rituais há 2.500 anos não é o mesmo vinho que bebemos na mesa com a comida, era muito mais forte e devia provocar alucinação como a da Agave, que arranca a cabeça do filho Penteu confundindo com leão, e como a ayahuasca provoca. Queríamos encontrar em nós a origem do teatro, nosso corpo, no nosso sistema nervoso, queríamos origem do teatro porque é disso que trata a última das tragédias, precisávamos reinventar o teatro aqui e agora.

Entrei em cena no início dos anos 1990, sempre quis estar dentro de um "movimento cultural" (a tropicália marcou muito a minha infância nos anos 1960), o Oficina, quando cheguei, era completamente desacreditado, muito diziam que nunca ia voltar a cena... mas, quando estreamos, e principalmente com o Ham-let, que abriu o Teatro Oficina como é hoje, não existia nada parecido com o que estávamos fazendo e isso provocou uma série de preconceitos, alguns perduram até hoje, mas também da minha parte não ficou barato, também criei preconceitos, um deles era ao chamado teatrão, o que acho hoje em dia uma bobagem, em qualquer teatro há a criação, ela pode ser diferente da minha, só isso, e alguém, com certeza, gosta mais daquele teatrão do que do teatro que produzo, mesmo sendo esse um grande trabaIho artístico, como o caso do Oficina, que pode-se dizer um dos melhores do mundo. Acredito no trabalho que realizamos e por isso nunca saí do Oficina, mesmo com toda a dificuldade de grana pra manter o teatro, a companhia, a mim mesmo e a falta de um reconhecimento popular, me mantenho à frente deste trabalho por tanto tempo. Quando digo me mantenho à frente, sei que nunca foi sozinho ou que não é mérito só meu o Oficina ocupar o lugar 
que ocupa, foi dessa associação - não chamo de grupo porque são muitos grupos, de gerações diferentes que se ligam criando uma rede que faz o trabalho acontecer.

No Oficina não escolhemos papéis, somos de certa forma escolhidos pelo papel, principalmente depois da década de 2000 , quando veio um geração nova de artistas que participaram de Os sertões, as peças ficaram mais musicais - sempre teve um capricho em trilhas - mas o canto em coro ganhando cada vez mais a protagonização, o coro aumentou, com mais vozes as canções ganharam espaço e as peças viraram óperas de carnaval, a maioria das canções são composições originais trabalhada em roda nos ensaios, cantar não é o meu forte, mas com o trabalho em roda afinei, não posso dizer que canto, só consigo entrar no tom e no tempo da música, e quase sempre acerto na trave. Agora essa geração que fez Os sertões já é madura e outra geração, outro coro, sobre as mesmas bases, porém com as percepções da época, se formou e aqueles que sempre estiveram ganharam autonomia e vamos aumentando a rede e fazendo o Oficina novo de novo.

E tão importante como o canto, a dança, é a luta que o Oficina trava com o Grupo Silvio Santos, essa personagem que esteve presente, senão em todas, em quase todas as produções que realizamos. São 40 anos de uma luta única que motivou e certamente atrapalhou, pois são poucos os que encaram um grupo que luta contra um dos maiores magnatas da especulação vídeo-financeira, que tem um braço imobiliário que quer transformar o Bixiga, um bairro popular, com construções da primeira metade do século $X X$, em um bairro cheio de torres e, com isso, expulsar os moradores de um bairro central pra periferia. Já viram esse filme? Enquanto aguentarmos, vamos à luta.

Autor convidado 